\title{
GALPERIN: IMPLICAÇÕES EDUCACIONAIS DA TEORIA DE FORMAÇÃO DAS AÇÕES MENTAIS POR ESTÁGIOS
}

\author{
AlEXANDRE ReZENDE* \\ Hiram VAldes*
}

\begin{abstract}
RESUMO: Estudo teórico que se dedica à análise das implicaçôes pedagógicas da teoria de Galperin sobre a Formação das Açôes Mentais por Estágios, discorrendo sobre a utilização de ferramentas cognitivas como recursos auxiliares para o pensamento e a promoção da aprendizagem. Galperin critica os modelos de ensino adotados pela escola, apresentando como alternativa o modelo formativo-conceitual, que preconiza o aprender por meio da prática, não só a fazer, mas a compreender e depois a explicar como e porque age desta ou daquela maneira diante de determinada situação-problema. O objetivo é ensinar a aplicar um esquema de referências conceituais (dicas) dirigidas para a aquisição de um método global de análise do conteúdo a ser aprendido (identificação dos invariantes). O aprendiz deve descobrir a melhor maneira de conjugar, ao mesmo tempo, todas as características da ação (orientação, execução, problema e contexto), tomando a decisão sobre como agir para resolver o problema.
\end{abstract}

Palavras-chave: Galperin. Modelo de ensino. Formação de conceitos. Base orientadora da ação. Teoria de formação das ações mentais por estágios.

\section{GALPERIN: PEDAGOGICAL IMPLICATIONS OF THE THEORY OF THE STEPWISE FORMATION OF MENTAL ACTIONS}

ABSTRACT: This paper is a theoretical study on the analysis of the pedagogical implications of the theory of the stepwise formation of mental actions, proposed by Galperin. It discusses the use of

\footnotetext{
* Professor da Faculdade de Educação Física da Universidade de Brasília (UNB). E-mail: rezende@unb.br

** In memoriam. Professor do Programa de Pós-Graduação da Faculdade de Ciências da Saúde da UNB.
} 
Galperin: implicações educacionais da teoria de formação das ações mentais...

cognitive tools as auxiliary resources to think and promote learning. Galperin criticizes the teaching models adopted by school and, as an alternative, he proposes the conceptual-formative model that preconizes learning through practice, not only by acting but also by understanding and then explaining why and how one acts in this or that way when faced with a certain problematic situation. The objective is to teach how to apply a scheme of conceptual references (hints) directed to the acquisition of a global method to analyze the content to be learned (basic unit). Learners must find a better way to combine all the characteristics of the action (orientation, execution, problem and context) at the same time, and make their decision about how to act to solve a problem.

Key words: Galperin. Thinking. Teaching method. Concept formation. Orienting base of an action. Teaching through the theory of stepwise formation of mental actions.

\section{Introdução}

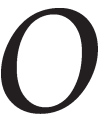

presente estudo teórico dedica-se à análise das implicações pedagógicas da Teoria de Formação das Ações Mentais por Estágios, proposta por Galperin e seus colaboradores, decorrentes da nova compreensão sobre o processo de desenvolvimento do pensamento, mais especificamente, sobre a formação de conceitos. Preocupadas em ampliar a efetividade do processo de aprendizagem de novos conhecimentos, as pesquisas de Galperin indicaram a necessidade de uma revisão dos modelos de ensino até então adotados pela escola.

Haenen (2000, p. 95) relata que, no início da década de 1950, Galperin e colaboradores investigaram o processo de aprendizagem das habilidades relacionadas à escrita, testando a eficiência de um método de ensino baseado na dissecação dos grafemas do alfabeto cirílico em segmentos gráficos. A proposta estava fundamentada nas idéias de Vigotski acerca da influência do conceito de unidades de análise no desenvolvimento do pensamento. Segundo Vigotski, a capacidade de identificar a unidade de um fenômeno é um produto da análise que preserva as características básicas do fenômeno como um todo.

Interessado em estudar como esse e outros conceitos de Vigotski (mediação e interiorização, por exemplo) poderiam ser operacionalizados e incorporados aos métodos de ensino, Galperin se propõe a avaliar a utilização de ferramentas cognitivas que forneçam ao aprendiz re- 
cursos auxiliares para o pensamento, verificando se contribuem para a promoção efetiva da aprendizagem (Werstch, 2000, p. 103).

Segundo Werstch (idem, ibid.), as idéias de Galperin causaram um grande impacto na psicologia russa; estudos experimentais em larga escala foram desenvolvidos por Elkonin, Davydov e colaboradores, nas décadas de 1960, 1970 e 1980. Os resultados obtidos nesses estudos são similares, indicando que as crianças desenvolveram habilidades, pautadas numa generalização conceitual, que se revelavam não apenas consistentes, como também transferíveis para outros domínios.

Em função disso, Gulmans et al. (1995, p. 81) afirmam que, atualmente, a psicologia russa deve ser compreendida a partir das idéias de Vigotski e das novas contribuiçôes de Galperin, que se dedica a aprofundar empiricamente os conceitos oriundos da teoria sócio-histórica, principalmente no que se refere às implicações educacionais. Haenen (2000, p. 93) e Werstch (2000, p. 103) reforçam essa posição ao apresentarem Galperin como o membro mais proeminente da última geração de psicólogos que tiveram contato pessoal com Vigotski.

Apesar do destaque obtido junto aos seus pares, Haenen (op. cit.) lamenta o fato de Galperin, até o momento, permanecer pouco difundido na psicologia educacional ocidental. Segundo Werstch (op. cit.), o único país do ocidente onde suas idéias têm sido discutidas é a Holanda.

A revisão bibliográfica abrange todo o material publicado sobre da teoria de Galperin, acerca da formação das ações mentais por estágios, em revistas e livros, disponíveis em inglês ou espanhol, sistematizando e divulgando seus conceitos e aplicações. As principais fontes de consulta são os periódicos Soviet Psychology, que depois passa a se chamar Journal of Russian and East European Psychology; Soviet Education and Human Development; além dos livros da Biblioteca de Psicologia Soviética, coleção publicada em espanhol com a obra dos fundadores da psicologia russa.

\section{Crítica ao modelo de ensino tradicional}

Os princípios que fundamentam a Teoria de Formação das Ações Mentais por Estágios têm uma relação direta com a crítica de Galperin (1989c, p. 67-69) aos modelos de ensino até então adotados pela escola.

$\mathrm{O}$ modelo tradicional de ensino reserva para o professor as seguintes tarefas: a) explanação dos conceitos a serem aprendidos, deta- 
Galperin: implicaçôes educacionais da teoria de formação das ações mentais...

lhando a lógica de raciocínio e os pressupostos nos quais se fundamenta; b) demonstração do processo de formação dos conceitos, detalhando a sua origem e evolução até o estágio no qual estão sendo ensinados; c) exemplificação dos conceitos, detalhando sua aplicação a uma série de situaçôes particulares pertinentes. $\mathrm{O}$ aluno, por sua vez, deve acompanhar o raciocínio do professor em cada uma dessas tarefas com a responsabilidade de: a) retirar as dúvidas; b) memorizar as informaçoes; c) aprender a utilizar as fórmulas que explicitam a aplicação dos conceitos em determinadas situaçōes.

Segundo Galperin (idem, p. 67), a necessidade de memorização dos conceitos teóricos, apresentados pelo professor de uma forma abstrata, dissociada da realidade prática, compromete a qualidade da aprendizagem obtida por meio do modelo de ensino tradicional.

Mesmo que o professor recorra a diversos exemplos, que demonstrem a aplicação prática dos conceitos, os alunos permanecem na condição de observadores, apenas acompanhando a apresentação de um raciocínio pronto e acabado. A rigor, até o momento, os alunos permanecem passivos; não precisam pensar (resolver uma situação-problema), muito menos agir. Em seguida, o professor passa uma série de exercícios, nos quais os alunos devem demonstrar que são capazes de realizar todo o processo de forma autônoma. Quais são, porém, as informações que os alunos dispóem para direcionar sua ação?

Enquanto os exercícios seguirem o formato de tarefas, realizadas de uma forma automática, e não de situações-problema, que exigem a participação ativa do pensamento associado com a ação, mantém-se o inconveniente do aprendiz, muitas vezes, estar completamente alheio aos componentes de orientação implícitos à ação, concentrando-se somente nos aspectos operacionais. Nessa perspectiva, o processo de aprendizagem permanece lento, desgastante e, geralmente, sem motivação.

$\mathrm{Na}$ escola, como o modelo de ensino tradicional adota uma forma de transmissão do conteúdo pautada no conceito em si mesmo (teoria), costuma-se utilizar um pequeno número de ações práticas, geralmente as do tipo mais simples, dirigidas apenas para aspectos materiais. Todo o resto do edifício do conhecimento é erigido com aspectos exclusivamente mentais e abstratos, totalmente dissociados das formas materiais onde se aplicam.

Repare que a exemplificação, principal recurso do modelo tradicional para estabelecer a relação entre os aspectos teóricos e os práticos, 
não resolve essa questão, pois o papel da dimensão prática para a aprendizagem não se resume a uma vinculação arbitrária, apenas com finalidade ilustrativa, mas envolve a consideração da relação funcional existente entre o conceito mental e a realidade concreta, a partir da qual foi criado e que lhe confere sentido.

Deve-se tomar cuidado para não oferecer às crianças situações práticas artificiais, nas quais tanto as características objetivas como a influência dos aspectos contextuais perderam seu caráter genuíno (Galperin, 1989b, p. 47).

Note, também, que existe um nítido contraste entre, de um lado, o nível de exigência no momento da avaliação final da aprendizagem, no qual o aprendiz deve demonstrar que é capaz de aplicar de forma independente o conceito mental a todas as situaçóes cabíveis e, de outro lado, a natureza das atividades realizadas ao longo do processo de ensino, que apenas proporcionaram a possibilidade de observar uma das possíveis aplicaçôes particulares dos conceitos. Isso também vale para a forma de participação do aprendiz, passiva durante o ensino, mas ativa na avaliação (Galperin, 1989a, p. 27).

Outra crítica de Galperin (1975, p. 88) ao modelo de ensino tradicional aponta para a precocidade da exigência de internalização do conceito: desde o início do processo de ensino, a participação do pensamento na aprendizagem ocorre de maneira totalmente interna.

\section{Crítica ao modelo de ensino aberto}

No caso do modelo de ensino aberto, que surge na escola como uma crítica ao modelo tradicional, a estrutura de ensino, ao invés de enfatizar a aprendizagem de determinados conceitos teóricos, dirige-se para a prática, investindo no desenvolvimento da capacidade de descoberta (aprender a aprender). O papel do professor é incentivar o aprendiz a observar, despertando sua curiosidade e desafiando-o a pesquisar e explicar determinados conceitos. Nessa nova estrutura, não há necessidade de exemplos, pois o aprendiz parte da própria experiência. Porém, como o nível de habilidades do aprendiz interfere diretamente na qualidade das experiências vividas, os resultados finais são diferenciados de acordo com o potencial de cada um.

A afirmação de que o esquema de ação por descoberta oferece a oportunidade para repetir várias vezes a mesma tarefa, como também 
Galperin: implicaçôes educacionais da teoria de formação das ações mentais...

para exercitar diversas habilidades diferentes, contribuindo, dessa maneira, para desenvolver a independência e autonomia de ação do aprendiz, é totalmente infundada. A experiência prática somente assume um caráter cumulativo, que beneficia o sujeito, quando o aprendiz é capaz de organizá-la segundo alguns conceitos mentais.

A familiaridade com as situações-problema pode desenvolver a capacidade de reconhecer algumas situaçôes, nas quais uma determinada resposta demonstrou, em momentos anteriores, ser a que apresenta a maior probabilidade de sucesso. Note que tal atitude ainda está distante do propósito de desenvolver a capacidade de colocar o pensamento em ação (que habilite o aprendiz a selecionar referências concretas para tomar uma decisão consciente sobre o que fazer diante de uma situação-problema), limitando-se ao reconhecimento de um padrão e à utilização de uma resposta automática.

Atenção: não se pode atribuir às condições objetivas da ação propriedades formativas em si mesmas, como se apenas a oportunidade de contato com tais aspectos materiais, expressos na situação-problema, fossem suficientes para fundamentar o processo de assimilação de novos conceitos. A proposta de aprender fazendo tem a vantagem de recuperar a motivação, muitas vezes perdida pelo modelo tradicional de ensino (centrado na teoria), como também o mérito de reconhecer que os conceitos mentais devem estar correlacionados com sua aplicação prática. Por outro lado, não consegue construir a interação necessária entre a prática e a teoria, limitando-se a uma apologia do fazer prático.

Sendo assim, enquanto o modelo tradicional apenas oferece uma descrição geral (teórica) do melhor caminho a ser seguido (well-trodden path), o modelo de ensino aberto se propóe a estimular o aprendiz a descobrir por si só o caminho a seguir (tentativa e erro). Nesse caso, Galperin faz um alerta: atenção, não se trata de simplesmente iniciar o processo de ensino pela aplicação prática do conhecimento. No modelo de ensino proposto por Galperin (1989c, p. 69), o conhecimento é obtido por meio da ação, na medida em que o sujeito, para resolver a situação-problema, tem que aprender a empregar determinados conceitos e, paralelamente, a observar a influência destes conceitos sobre o contexto em que a ação está inserida.

Sendo assim, de acordo com a avaliação crítica geral de Galperin à escola (1992c, p. 71), as dificuldades de aprendizagem, geralmente 
atribuídas ao aprendiz, seja em função da falta de prontidão maturacional, de lacunas no processo de desenvolvimento ou de diferenças individuais no nível de habilidades, na verdade podem ser decorrentes de limitaçôes nos modelos de ensino adotados, que não fornecem as condiçōes necessárias para aprendizagem.

O modelo de ensino pautado na teoria de formação das ações mentais (conceitos) deve seguir uma diretriz que estabelece a progressão das formas externas de expressão - ação e linguagem - para formas internas de pensamento.

\section{O modelo de ensino formativo-conceitual}

O novo modelo de ensino ativo de Galperin (1975, p. 88), intitulado "Teaching through a step-by-step formation of mental actions and concepts", está pautado nas etapas que, segundo a teoria sócio-histórica, caracterizam a formação dos conceitos mentais, adotando outros princípios em relação à organização do processo de aprendizagem:

a) o conhecimento a ser assimilado ou a habilidade a ser aprendida são considerados como ponto de partida para ação, sendo apresentados sob a forma de situaçôes-problema; logo, desde o início, ainda durante a etapa de apresentação, o conhecimento é operacionalizado na prática; o que para o modelo tradicional era a última etapa, utilizada mais com um caráter de avaliação, passa a ser a primeira etapa, assumindo uma dimensão formativa até então desprezada;

b) a seleção e organização das atividades devem ser adequadas ao potencial dos aprendizes, de forma que qualquer um, com um mínimo de conhecimentos e habilidades preliminares, seja capaz de ser bem sucedido na descoberta da solução do problema; ao contrário do modelo tradicional de ensino, que se dirige unicamente para o resultado final, o novo modelo prevê etapas intermediárias correspondentes aos diversos estágios do processo de formação dos conceitos mentais;

c) a seqüência de apresentação das atividades deve seguir um mapeamento que possibilite ao aprendiz alcançar êxito na solução do problema imediatamente, antes que a aprendizagem do co- 
Galperin: implicaçôes educacionais da teoria de formação das ações mentais...

nhecimento se processe completamente; isto se dá porque a atividade não assume o caráter de um exercício em si mesmo, e sim de uma oportunidade para vivenciar determinada situaçãoproblema e aprender sobre a lógica operacional dos conceitos naquela situação em particular;

d) as situações-problema estão diretamente correlacionadas entre si, direcionando o sujeito para a pesquisa dos aspetos gerais, comuns a todas as situações ou determinados grupos de situaçóes, que se caracterizam como invariantes da prática (referenciais que direcionam a ação).

De acordo com esse modelo de ensino, denominado nesse estudo de formativo-conceitual, quando o aprendiz tem acesso ao significado operacional do conceito e à oportunidade para experimentar sua utilidade na solução dos problemas, não precisa memorizar um conjunto de fórmulas e suas possíveis aplicações. $\mathrm{O}$ processo de internalização dos conceitos assume uma dimensão funcional e não apenas informativa, além de, progressivamente, tornar o aprendiz capaz de deduzir as fórmulas sempre que for necessário.

Esse nível de compreensão também garante a fixação do conteúdo, pois, ao contrário do modelo tradicional de ensino, no qual o aprendiz, mesmo quando tem sucesso na aprendizagem, tende a esquecer os conceitos aprendidos, a assimilação da lógica de formação dos conceitos permite ao aprendiz desenvolver um método de estudo que lhe possibilita, a qualquer momento, seguir novamente os mesmos passos analíticos que conduziram à formulação inicial dos conceitos.

Sendo assim, ao invés de aprender a repetir, como está definido pela estrutura de ensino proposta pelo modelo tradicional, o modelo de ensino formativo-conceitual se propóe a assegurar ao aprendiz a oportunidade de aprender, por meio da prática, não só a fazer, mas, progressivamente, a entender e depois a explicar como e porque age desta ou daquela maneira. Posteriormente, o aprendiz deve também ser capaz de corrigir tanto a própria ação como a dos demais, assumindo, em tese, a posição que o modelo tradicional prescreve para o professor.

$\mathrm{O}$ modelo de ensino formativo-conceitual favorece o desenvolvimento de outras propriedades mentais até então não contempladas pelo modelo tradicional: a) a consciência, capacidade de interpretar as relações entre cada uma das situaçóes específicas e o seu contexto de ocor- 
rência, e b) a aplicação automática, capacidade de transferir a aprendizagem para outras situações equivalentes, que respondem da mesma maneira à aplicação dos conceitos referenciais fornecidos pela base orientadora da ação.

Considerando que a organização do processo de ensino (seleção das situações-problema; apresentação da base orientadora da ação; acompanhamento e reorganização do processo como um todo) lida com aspectos objetivos e racionais que, de certa forma, não dependem diretamente dos sujeitos, pode-se afirmar que a aprendizagem é organizada iniciando pelos aspectos externos, objetivos e materiais, para terminar num nível interno, mental e abstrato, no qual as ações sofrem um processo de abreviação, simplificando-se, e de automatização, ganhando agilidade, ao mesmo tempo em que podem ser facilmente monitoradas.

Note que o objetivo é aprender a aplicar um esquema de referências conceituais para orientar a ação e não simplesmente aprender os conceitos em si mesmos. O aprendizado é resultante da ação empreendida com apoio do esquema de orientação conceitual e não da assimilação do conceito propriamente dito, exclusivamente num plano mental e teórico.

A performance correta não é um objetivo em si mesmo e sim um princípio do modelo de ensino formativo-conceitual para conduzir a aprendizagem; se o aprendiz apresenta uma performance correta não significa que aprendeu, mas, sim, que está sendo capaz de colocar em prática as orientações fornecidas pela base orientadora para organizar a ação, garantindo que a ação empreendida é consciente e racional.

No modelo de ensino formativo-conceitual, a ação não é formada de uma maneira fragmentada, parte por parte, nem isolada do contexto em que está inserida, mas a partir de um esquema conceitual que conjuga, ao mesmo tempo, todas as características da ação: orientação, execução, situação-problema e contexto.

O caráter ativo do modelo de ensino formativo-conceitual facilita a aprendizagem e torna o conhecimento acessível numa faixa etária cada vez mais precoce, comportando um volume e uma complexidade de informações significativamente maiores, sem, contudo, perder a qualidade do ensino e sem gerar os inconvenientes geralmente apontados pela especialização prematura da ação (Galperin, 1975, p. 92).

A antecipação dos conteúdos não se deve à descoberta de habilidades até então desconhecidas, que agem como pré-requisito para a 
Galperin: implicaçôes educacionais da teoria de formação das ações mentais...

aprendizagem, mas no potencial latente dos aprendizes que não era adequadamente aproveitado ou corretamente estimulado pelos modelos de ensino até então utilizados.

Conceitos básicos da Teoria de Formação das Ações Mentais por Estágios

A expressão ação mental sugere a existência de uma correlação entre dois aspectos usualmente considerados dissociados entre si. Enquanto o termo ação relaciona-se com uma dimensão prática, influenciada pelas condições materiais e objetivas (externas), o termo mental referese a algo que acontece numa dimensão psicológica (interna), que envolve elementos de natureza abstrata e imaterial.

A pedagogia, por sua vez, dedica-se ao estudo do método de ensino mais indicado para promover a aprendizagem de conceitos novos e cada vez mais complexos, considerados importantes para o desenvolvimento do pensamento.

As questôes supracitadas estão diretamente relacionadas. A pedagogia somente chegará a uma conclusão adequada para a discussão metodológica sobre o processo ensino-aprendizagem quando conhecer quais são as principais características das ações mentais e qual é a dinâmica do processo de formação dessas ações.

Qual é, porém, o significado atribuído pela Teoria de Formação das Ações Mentais por Estágios para a expressão ação mental? De acordo com Galperin (1989a, p. 26), deve-se fazer uma distinção entre dois tipos de ações: ações materiais e ações mentais.

As ações materiais restringem-se à prática em si mesma, situandose num âmbito reflexo, no qual a ação do sujeito é definida como uma resposta eliciada automaticamente a partir da identificação e manipulação das características objetivas dos estímulos externos - esse tipo de ação possui pouca influência sobre o desenvolvimento do pensamento.

As ações mentais, por sua vez, referem-se à prática direcionada por um conceito mental, portanto, uma prática consciente, na qual a ação do sujeito volta-se para a aplicação e o teste da eficiência das indicações operacionais fornecidas pelo conceito para a solução de uma situação-problema. Nas ações mentais rompe-se a dissociação entre o 
pensamento e a ação, construindo-se uma mediação que viabiliza a potencialização e o aumento da qualidade de ambos.

Ao utilizar a expressão ação mental, Galperin (1989a, p. 7) contraria a compreensão usual dos aspectos mentais como fenômenos imateriais. $\mathrm{O}$ destaque conferido às ações mentais é devido, justamente, ao seu caráter ambivalente e complexo. As ações mentais possuem, de maneira implícita, um conteúdo objetivo e material, mediado pela influência direta dos conceitos mentais que a elas se aplicam.

Os aspectos materiais e mentais se constituem em elementos de um mesmo e único processo, que se desenvolve no sentido de promover a transformação progressiva dos aspectos materiais em mentais, fomentando a interiorização de conceitos, inicialmente de caráter operacional, para uma forma exclusivamente mental, que nunca perderá sua interligação com a prática.

De acordo com Galperin (1989b, p. 46), separar a ação mental do seu conteúdo objetivo e prático é claramente um erro; da mesma forma que não se pode reduzir a ação mental à dimensão operatória, restrita à mera manipulação das condições objetivas que caracterizam uma situação em particular. Na verdade, o estudo da formação das ações mentais somente é possível quando se considera a influência exercida pelos aspectos objetivos sobre as ações do indivíduo.

O conteúdo objetivo e material de uma determinada situaçãoproblema comporta um conjunto de propriedades que conjugam as características específicas do problema em si, mesmo com as influências contextuais onde está inserido, caracterizando um sistema organizado de estímulos, que desafia o sujeito a descobrir a melhor maneira de agir para conseguir encontrar na prática a solução do problema. A partir dessa compreensão, pode-se afirmar que, se as ações mentais não se reduzem ao conteúdo objetivo, tampouco podem ser completamente indiferentes a ele (Galperin, 1989b, p. 48).

Segundo Talízina (1988, p. 47), para se desvendar os mecanismos internos que caracterizam a atividade cognoscitiva não é suficiente verificar a capacidade de resolver determinadas situações-problema, pois a obtenção de uma resposta correta não significa necessariamente raciocínio correto; o indivíduo pode recorrer a tipos substancialmente diferentes de raciocínios, às vezes incorretos, para chegar à solução de uma 
Galperin: implicaçôes educacionais da teoria de formação das ações mentais...

situação-problema. Outras vezes, o indivíduo consegue resolver corretamente a situação-problema, porém, não tem consciência do porquê, nem sabe muito bem explicar como. Em todas essas situaçóes, o aprendiz não desenvolve um método de ação eficaz.

Cada vez mais fica evidente que a ação mental não é algo exclusivamente abstrato, mas que se dirige para uma determinada situaçãoproblema, tentando resolvê-la na prática. Além de considerar os aspectos objetivos que caracterizam tal situação, o sujeito também se vale de um modelo conceitual de referência que lhe permite discriminar quais são os aspectos essenciais que devem ser levados em consideração na organização da ação.

\section{A estrutura das açóes mentais}

$\mathrm{Na}$ descrição das características das ações mentais, é possível fazer uma diferenciação entre dois tipos de componentes: execução e orientação. Os componentes relacionados com a execução dependem do nível de habilidade do sujeito e sofrem uma influência direta do sistema formado pelas condiçōes materiais próprias de cada situação-problema. Os componentes relacionados com a orientação dependem do nível de inteligência do sujeito e sofrem uma influência direta do tipo de conceitos mentais que são colocados à disposição do sujeito para resolver a situação-problema (Galperin, 1989b, p. 47).

Os componentes de execução e orientação são, na verdade, duas nuanças de uma mesma ação. Externamente, esses componentes podem parecer duas ações independentes, até mesmo porque essa impressão é reforçada pelo fato de cada um desses componentes seguir um processo específico de formação, que não é coincidente na sua conclusão, ou seja, um pode estar mais desenvolvido que o outro; porém, internamente, são interdependentes e indissociáveis (idem, ibid., p. 48-49).

Quando a aprendizagem dirige-se apenas para o conteúdo objetivo e material de uma determinada situação-problema, não significa que a ação está destituída dos componentes de orientação; nesse caso, a ênfase situa-se nos componentes de execução, que são treinados em si mesmos, dentro de uma situação padrão que minimiza a influência dos aspectos contextuais e conduz à formação de hábitos.

Como, nessa situação em particular, o componente de orientação é muito específico, geralmente descritivo, ele perde o destaque. A 
padronização descaracteriza o exercício como uma situação-problema, pois se limita a exigir o cumprimento de uma determinada tarefa. Em outras palavras, não existe mais espaço para a tomada de decisão, o que deve ser feito é estabelecido previamente, restando ao sujeito apenas executar (idem, ibid., p. 46-47).

Esse nível de aprendizagem, dirigido para os componentes de execução, limita-se aos aspectos exteriores das ações, como se em tais situações não existisse nada de psicológico; porém, toda e qualquer ação na qual o sujeito se confronta com uma realidade dinâmica e aberta traz implícita uma forte influência dos aspectos mentais, que estabelecem uma correlação entre os aspectos objetivos da situação-problema e as alternativas de ação existentes, considerando também o nível de habilidade do sujeito (idem, ibid., p. 47-48).

Ao longo do processo de formação das ações mentais, os componentes de orientação sofrem transformações. Ao ser aplicado a diferentes situações-problema, o componente de orientação passa por um processo de diferenciação, onde se destacam, cada vez mais, os aspectos invariantes, que passam a servir de ligação entre a análise da situaçãoproblema e a tomada de decisão sobre o que fazer. Progressivamente, os aspectos invariantes unificam-se em torno de uma imagem ou de um conceito abrangente que passa a operar como um sistema geral de referência, aumentando significativamente a precisão dos componentes de orientação da ação (Galperin, 1992c, p. 62).

Se considerarmos que o aprendiz também desenvolve a capacidade de identificar pronta e agilmente as situações-problema nas quais os invariantes estão presentes, a aplicação dos componentes de orientação torna-se muito mais ágil, quase automática, de forma que, tão logo a situação-problema é reconhecida, a ação já é desencadeada seguindo os parâmetros conceituais já assimilados dos componentes de orientação (idem, ibid.).

De uma maneira geral, essas mudanças ocorrem na formação de qualquer tipo de ação mental, mas, na prática, o nível de aperfeiçoamento dos conceitos mentais assimilados varia de acordo com: a) a natureza das açōes mentais; b) o potencial dos aprendizes; c) o nível de complexidade da situação-problema.

Os vínculos entre os conteúdos de natureza psicológica e os conteúdos de natureza diversa são muito complexos, mas uma coisa se pode afirmar com certeza: tanto é incorreto considerar que a ação men- 
Galperin: implicaçôes educacionais da teoria de formação das ações mentais...

tal é um fenômeno totalmente não-psicológico, como também é incorreto considerá-la um fenômeno exclusivamente psicológico. Da mesma forma, o conteúdo objetivo da ação também se reflete na consciência, mas, ao mesmo tempo, é independente dela. Segundo Galperin (1989b, p. 48), o conteúdo psicológico das ações não pode ser estudado de forma dissociada do seu conteúdo não psicológico.

\section{Princípios gerais do modelo de ensino formativo-conceitual}

De acordo com a Teoria de Formação das Ações Mentais por Estágios, a formação das ações mentais não pode ser realizada pela mera associação de outros conceitos já formados, nem se dirigir diretamente para o nível mental que caracteriza sua forma final, sem que o sujeito tenha passado pela ação, pois corre o risco de assumir uma dimensão exclusivamente teórica, dissociada da prática.

Galperin (1989a, p. 29) afirma que a formação das ações, imagens e conceitos representa diferentes aspectos de um mesmo e único processo. Explorando essa propriedade, o modelo formativo-conceitual seleciona certas características do objeto, no caso a situação-problema (exigências objetivas relacionadas com as características contextuais), associadas às dicas e orientações fornecidas pelos conceitos mentais, para organizar uma base orientadora da ação que direcione os passos específicos que devem ser adotados na solução da situação-problema.

Elegendo como elo central da aprendizagem a prática, o modelo formativo-conceitual vê na ação um sistema completo de experimentação, que fornece elementos essenciais para o direcionamento da aprendizagem. Por meio da ação, o sujeito aplica e testa os esquemas referenciais que fundamentam a tomada de decisão, direcionam a execução e subsidiam a avaliação.

A conseqüência imediata de se fornecer ao aprendiz uma base orientadora da ação é o aumento do nível de eficiência da ação na solução da situação-problema. Esse, no entanto, é apenas o ponto de partida para uma série de outros estágios decorrentes da aprendizagem, que envolvem a diferenciação da ação e, principalmente, a interiorização das ações na formação de novos conceitos mentais.

Para cada estágio da aprendizagem existe um conjunto de propriedades correspondentes, que necessariamente devem ser desenvolvi- 
das para que o sujeito tanto tenha condições de dar continuidade ao processo, iniciando as fases posteriores, como também garantindo a possibilidade de transitar facilmente de um estágio para o outro (Galperin, 1989c, p. 78).

\section{Características da situação-problema - conceito de invariante}

A definição do tipo de situação-problema que se articula diretamente com o processo de ensino-aprendizagem não é algo fortuito, devendo estar pautado, de um lado, na análise das características do conhecimento em si mesmo e, de outro, na análise dos aspectos objetivos das próprias situações-problema.

Para o modelo formativo-conceitual, isto significa que há uma relação direta entre as características materiais das situações-problema e os estímulos que oferecem para o sujeito, ou seja, mudanças no tipo ou no contexto das atividades redundam no desenvolvimento de habilidades e conhecimentos diferentes.

Devemos, portanto, preservar determinados aspectos objetivos presentes na realidade quando se pretende desenvolver açôes mentais correspondentes, pois não é possível, por exemplo, desenvolver a formação de conceitos se o aprendiz não tiver a oportunidade de vivenciar situações nas quais tenha que aplicar esses conceitos na prática, aprendendo sobre as suas características como um instrumento para solucionar certos tipos de problemas concretos.

A partir do momento em que se concorda que as ações mentais somente contribuem para a aprendizagem quando o sujeito tem acesso ao seu conteúdo conceitual e o coloca em prática, o passo seguinte é discutir como incorporar tais princípios ao processo de ensino.

A proposta do modelo formativo-conceitual dedica-se à análise do conceito a ser ensinado, identificando um aspecto operacional geral, comum a todas as situaçôes - invariante -, que se constitui na essência da situação-problema, utilizando-o para direcionar a ação - esse modelo de ensino está centrado na consciência das propriedades aplicativas dos conceitos operacionais para solução do problema. Os conceitos referenciais que fazem parte dessa base orientadora da ação, em função do uso freqüente, tendem a ser diretamente percebidos pelo sujeito (Galperin, 1989b, p. 54). 
Galperin: implicaçôes educacionais da teoria de formação das ações mentais...

\section{Base orientadora da ação}

Tendo em vista suprir as lacunas existentes nos modelos de ensino até então utilizados pela escola, Galperin (1989c, p. 69) adota como princípio central do modelo formativo-conceitual assegurar que o aprendiz tenha acesso a todas as orientações necessárias para organizar as ações que mediatizam a aprendizagem.

Num primeiro momento, a abrangência das orientações depende de uma análise minuciosa da complexidade das relaçôes existentes entre: a) o sistema de condições objetivas que caracterizam a situaçãoproblema; b) o conhecimento das capacidades individuais de cada aprendiz; c) a avaliação da experiência anterior e d) o domínio dos conceitos e informaçôes que caracterizam o conteúdo a ser aprendido, sondando pré-requisitos e necessidades (Galperin, 1989c, p. 70).

No modelo formativo-conceitual, a principal função das orientações não consiste em fornecer um esquema preliminar de ação, que prescreva os passos que obrigatoriamente devem ser seguidos pelo aprendiz, e sim em orientá-lo na interpretação da situação-problema, capacitando-o para encontrar, na prática, a solução mais adequada para o problema - base orientadora da ação. De acordo com Galperin (1989b, p. 49), toda ação humana é orientada por um conjunto de conceitos específicos, que determinam a qualidade final da ação realizada.

Mesmo quando se confronta com situações objetivas totalmente arbitrárias, situadas unicamente num plano material, sem qualquer significado associado, o sujeito sempre age a partir de um modelo representativo que direciona sua ação. Nesse sentido, toda ação humana é formada com base em um modelo conceitual de referência, que não requer somente ser colocado em prática (execução), mas, também, ser submetido à verificação (Galperin, 1989b, p. 56).

Em termos objetivos, as orientações fornecidas pelo modelo de ensino formativo-conceitual assumem um papel auxiliar na aprendizagem, muito semelhante ao conceito de dica proposto por Vigotski. A definição de Zona de Desenvolvimento Proximal está articulada com o fornecimento de uma orientação adicional (dica), que auxilia o aprendiz a compreender e, conseqüentemente, resolver de forma adequada um problema que não era capaz de solucionar sozinho. A orientação do professor não fornece a resposta do problema e, sim, chama a aten- 
ção do aprendiz para um aspecto operacional do raciocínio e/ou da ação exigida pelo problema. Agindo ou raciocinando de acordo com a lógica implícita na orientação, o aprendiz revela-se capaz de concluir com êxito o processo de solução.

Cientes de que quanto maior for a possibilidade de aplicação do conceito operacional (dica), presente nas orientaçôes fornecidas ao aprendiz para a solução de um maior número de situações-problema particulares, mais importante é o papel que desempenha no direcionamento da ação e, conseqüentemente, na promoção da aprendizagem, os professores voltaram seus esforços para a descoberta de conceitos gerais, que estejam presentes em todas as situações particulares, ou em grupos de situações equivalentes, apresentando, dessa maneira, o maior alcance possível.

\section{Aspectos conceituais da base orientadora da ação}

A base orientadora da ação deve estabelecer a relação entre a parte material, representada pelos componentes de execução, e a parte mental da ação, que reúne os componentes de orientação e de execução, direcionando o sujeito para uma percepção clara e precisa da situação-problema e para a realização de uma ação consciente, referenciada em conceitos que buscam uma solução ideal da situação-problema (Galperin, 1989c, p. 70).

Como qualquer instrumento, a base orientadora da ação situa-se entre o sujeito e o objeto da ação, tendo como principal função fazer a mediação entre a ação e a solução da situação-problema (contexto de ocorrência da ação), fornecendo-lhe uma orientação acerca dos meios necessários para obter o êxito da ação (idem, ibid.).

A base orientadora da ação precisa ser colocada em prática. Talízina (1988, p. 135), por exemplo, adverte que é inútil esperar que se forme o pensamento matemático para começar a ensinar matemática, pois só o ensino de matemática conduz ao desenvolvimento do pensamento matemático.

Deve ficar claro, porém, que seus conceitos operacionais não determinam, de forma rígida e mecânica, todas as açôes do sujeito. Não se trata de uma tarefa como outra qualquer. $\mathrm{O}$ aprendiz continua tendo que resolver a situação-problema de forma independente, porém 
Galperin: implicaçôes educacionais da teoria de formação das ações mentais...

com o auxílio de alguns conceitos operacionais que norteiam a tomada de decisão sobre o que fazer. A base orientadora da ação conduz o aprendiz a testar a sua aplicação em diversas situações, contribuindo para a assimilação dos conceitos mentais a ela associados (idem, ibid., p. 78).

Note que o objetivo é aprender a aplicar o esquema de referências conceituais presente na base orientadora da ação para direcionar a ação na solução de uma determinada situação-problema. O aprendizado é resultante da ação empreendida com apoio do esquema de orientação conceitual e não da assimilação do conceito mental propriamente dito, exclusivamente num plano cognitivo e teórico.

Em seguida, o aprendiz deve testar a aplicação das orientações fornecidas para a solução de várias outras situações-problema equivalentes. Galperin (1989c, p. 66) ressalta que, como o modelo de ensino formativo-conceitual dirige-se para o processo de compreensão, o aprendiz, ao invés de exercitar as habilidades específicas de uma determinada situação-problema, deve exercitar a capacidade de aplicar as referências conceituais para a solução de todas as situações-problema que possuem uma estrutura comum ou aproximada.

Os conhecimentos e as habilidades adquiridas por meio do modelo formativo-conceitual podem ser divididos em duas partes diferentes: 1) uma que se refere ao domínio dos invariantes presentes nas ações mentais e outra 2) relacionada com os fatos concretos e particulares presentes em cada uma das situações-problema solucionadas ou não pelo aprendiz. A segunda parte, no tocante ao volume de informações e aos detalhes práticos, é consideravelmente maior do que a primeira; em contrapartida, a sua contribuição para desenvolvimento do pensamento é significativamente menor (Galperin, 1989a, p. 43).

Para o modelo de ensino formativo-conceitual o que está em questão não é a aprendizagem de um determinado conhecimento ou o desenvolvimento de uma habilidade em particular, mas a qualidade dessa aprendizagem e sua contribuição para a evolução do pensamento e da motricidade como um todo.

Nesse sentido, é também possível a utilização do modelo formativo-conceitual em níveis avançados de estudo, tendo em vista não a aprendizagem de uma habilidade ou um conhecimento em particular, mas tornar o aprendiz capaz de elaborar, de forma independente, a própria base orientadora da ação, criando condições para uma condução 
autônoma do processo de aprendizagem de novos conhecimentos (Galperin, 1992c, p. 73).

Isto se deve ao fato da aprendizagem, a partir do modelo de ensino formativo-conceitual, dirigir-se para a aquisição de um método geral de estudo e análise do conteúdo a ser aprendido. Quando o aprendiz adquire agilidade na elaboração e no emprego de tal método de análise, até então desorganizado ou assistemático, os recursos disponíveis para direcionar as açóes mentais ampliam-se consideravelmente, promovendo a transição do nível de desenvolvimento para um estágio qualitativamente superior (Galperin, 1992c).

No modelo de ensino formativo-conceitual, cada erro representa um entrave para a aprendizagem, na medida em que sinaliza a falta de condições que instrumentem o sujeito para alcançar êxito na ação. Diante do erro do aprendiz, compete ao professor: 1) observar a ação do aprendiz e identificar quais os conceitos da base orientadora da ação estão sendo desconsiderados, pesquisando novas maneiras de apresentação das orientações que levem o aprendiz a utilizá-las efetivamente na prática, eliminando totalmente os erros; ou 2) identificar novos pontos de referência que redefinam o conteúdo da base orientadora da ação, capacitando o aprendiz para executar corretamente a ação (Galperin, 1989a, p. 29).

A performance correta não é um objetivo em si mesmo, mas, sim, um princípio utilizado pelo modelo de ensino formativo-conceitual para conduzir a aprendizagem; se o aprendiz apresenta uma performance correta, não apenas numa situação em particular, mas em todas as situações equivalentes, significa que realmente aprendeu, pois é capaz de colocar em prática as orientações fornecidas pela base orientadora para organizar a ação, deixando claro que a ação empreendida é consciente e racional (Galperin, 1989c, p. 72).

A formação completa dos conceitos requer a transformação das ações em uma forma de expressão verbal, ensinando os alunos a resolver a situação-problema sem qualquer apoio dos elementos concretos, utilizando somente os conceitos mentais. Uma vez completamente assimilada, a ação mental pode facilmente ser abreviada e exteriorizada em qualquer uma das formas anteriores - verbal, materializada ou material. As ações também se tornam claramente conscientes e automáticas.

Por último, a base orientadora da ação deve ser diferenciada das orientações para ação que o sujeito já possui. Enquanto a base orientadora 
Galperin: implicaçôes educacionais da teoria de formação das ações mentais...

da ação é um modelo representativo externo da ação a ser desempenhada, as orientaçôes próprias do aprendiz são o reflexo desse modelo conceitual dentro da sua mente; antes de se tornarem um verdadeiro mecanismo psicológico de ação do indivíduo. As orientações próprias do sujeito demonstram a conexão existente entre os conceitos a serem aprendidos e a capacidade do aprendiz de compreendê-los, assimilá-los e aplicá-los na prática. Enquanto a base orientadora da ação se mantém constante, as orientaçôes próprias do sujeito variam de acordo com o refinamento obtido por meio da prática (idem, ibid., p. 81).

$\mathrm{Na}$ medida em que as orientaçōes próprias do sujeito se diferenciam, ganhando um caráter generalizado, o aprendiz adquire um repertório verbal variado e preciso de expressão, sua performance adquire uma forma abreviada e a aplicação da base orientadora da ação passa a ser automática.

\section{Dificuldades na elaboração da base orientadora da ação}

Segundo Galperin (1989c, p. 75), a maior dificuldade para a elaboração da base orientadora da ação é a identificação dos conceitos operacionais (invariantes) que direcionam a ação do aprendiz, garantindo a descoberta da solução para a situação-problema logo nas primeiras tentativas. Quando o sujeito não é capaz de, com as orientações fornecidas, encontrar a melhor alternativa possível de ação, deve-se rever o conteúdo da base orientadora da ação, corrigindo uma ou mais das falhas relacionadas abaixo:

a) a base orientadora da ação, para ser colocada em prática, pressupõe determinados pré-requisitos que os aprendizes ainda não desenvolveram;

b) a base orientadora da ação é formada por conceitos que estão além da capacidade de compreensão dos aprendizes;

c) a base orientadora da ação é formada por conceitos que não possuem um caráter operacional e, apesar dos aprendizes compreenderem sua lógica, não conseguem relacioná-los com a prática.

Karpova (citada por Galperin, 1989c, p. 77-78) apresenta os argumentos que justificam o aumento progressivo de habilidade dos su- 
jeitos na aplicação dos conceitos referenciais da base orientadora da ação para a descoberta da solução da situação-problema:

a) familiarização com o novo método de ação, aprendendo rapidamente a seguir instruções esquemáticas;

b) repetição da ação em diferentes situações-problema, facilitando a assimilação dos conceitos operacionais que compõem a base orientadora da ação;

c) conhecimento global da ação (como um todo): tendo ciência das exigências que caracterizam o próximo estágio, o aprendiz é capaz de organizar antecipadamente a ação;

d) articulação entre os estágios da ação, estabelecendo os vínculos de um estágio para o outro que, progressivamente, fazem desaparecer as fronteiras, contribuindo para a ação assumir uma forma abreviada;

e) compreensão da lógica que fundamenta a ação, permitindo a automatização do uso dos referenciais conceituais.

Tanto a abreviação como a automatização da ação, indicadores que sinalizam a eficiência da aprendizagem e a melhoria da performance, não significam que os estágios que caracterizam a ação foram eliminados, mas, sim, que o sujeito se torna capaz de coordená-los de forma que ocorram simultaneamente. Como a estrutura da ação permanece inalterada, o modelo de ensino formativo-conceitual não precisa sofrer alteraçóes, mantendo-se válido e eficiente para aperfeiçoar mais ainda o nível de habilidades do aprendiz (Galperin, 1989c, p. 79).

\section{Considerações finais sobre o modelo formativo-conceitual}

O modelo de ensino formativo-conceitual coloca em jogo uma série de operaçôes, que determinam a dinâmica e o resultado do processo de formação de novas ações mentais, compreendendo os seguintes passos:

a) analisar as exigências ditadas pelos aspectos objetivos que caracterizam a situação-problema e a lógica geral que fundamenta o raciocínio que conduz à solução, identificando os aspectos estruturais invariantes; 
Galperin: implicaçôes educacionais da teoria de formação das ações mentais...

b) pesquisar conceitos operacionais completos que direcionem a ação do aprendiz para busca de uma solução da situação-problema, diretamente associada aos invariantes identificados anteriormente, construindo a base orientadora da ação;

c) selecionar a forma de apresentação da base orientadora da ação, levando em consideração os recursos disponíveis e as características do aprendiz, da situação-problema e do contexto em que se insere - atenção: independente da forma de apresentação escolhida, deve-se garantir ao aprendiz a possibilidade de consultar, a qualquer momento, durante a prática, o conteúdo da base orientadora da ação;

d) organizar o ambiente de aprendizagem o mais próximo possível do contexto real ligado aos conhecimentos e/ou habilidades a serem aprendidas, levando o aprendiz a experimentar na prática os conceitos da base orientadora da ação - os quatro primeiros itens constituem o subsistema de condições que interferem diretamente na assimilação e interiorização de novas ações mentais;

e) analisar os resultados da ação, verificando se o aprendiz é capaz de, com o apoio da base orientadora da ação, resolver adequadamente a situação-problema; caso contrário, rever os itens anteriores até alcançar um resultado positivo - subsistema de checking;

f) diversificar as situações-problema, incluindo aquelas equivalentes ou próximas, que também possam ser resolvidas a partir da utilização dos conceitos operacionais fornecidos pela base orientadora da ação, demonstrando ter flexibilidade de aplicação - subsistema que se volta para o refinamento tanto das propriedades aplicativas dos conceitos, como das habilidades perceptivomotoras envolvidas na execução da ação;

g) à medida que o aprendiz tem a oportunidade de testar repetidas vezes a aplicação da base orientadora da ação para resolver mais e mais situações-problema, os componentes de orientação e execução da ação vão se tornando cada vez mais integrados, até que, posteriormente, todo o esquema de conceitos operacionais que compõem a base orientadora da ação transforma-se em conceitos mentais, passíveis de serem manipulados referencialmente (Galperin, 1992c, p. 62). 
Talízina (1988, p. 48) faz menção a dois tipos principais de programas de direção do processo de ensino-aprendizagem: o principal e o regulador. O programa de direção principal é preparado antes que o processo de ensino comece, tendo como principal componente a base orientadora da ação, enquanto que o programa de direção regulador somente pode ser elaborado ao longo do processo de ensino, tomando por base a análise das ações do aprendiz, para reorganizar os aspectos falhos - muitas variáveis que intervêm diretamente na aprendizagem surgem apenas durante a realização da proposta de ensino.

Os programas de direção do processo de ensino, tanto o principal como o regulador, devem, num primeiro momento, analisar os objetivos situados num nível macro, determinado pelo caráter das ações mentais a serem aprendidas e o contexto social em que se inserem - aspectos objetivos, externos ao aprendiz. Em seguida, deve-se analisar os objetivos situados num nível micro, relacionado com os interesses e as expectativas do grupo e de cada aprendiz em particular - aspectos subjetivos, que envolvem a personalidade de cada um (Talízina, 1988, p. 49).

\section{Críticas ao modelo de ensino formativo-conceitual}

Segundo Galperin, ao apresentar e defender os princípios que fundamentam a Teoria de Formação das Ações Mentais por Estágios, às vezes se deparava com opositores que apresentam as seguintes objeçôes:

- A base orientadora da ação caracteriza-se como um conhecimento pronto e acabado a ser assimilado pelo aprendiz. No entanto, o modelo formativo-conceitual dirige-se para instrumentar o aprendiz a desenvolver um método geral de ação. O objetivo não é assimilar os conceitos que compõem a base orientadora da ação, mas, sim, utilizar as referências operacionais fornecidas por eles para direcionar as ações mentais na análise e resolução das situações-problema.

- O professor perde o papel de destaque como um auxiliar importante para a aprendizagem (atitude passiva), transferindo as atribuiçôes de orientação para a base orientadora da ação. Quando as pessoas assistem à apresentação dos princípios do modelo formativo-conceitual têm a impressão de que há uma exaltação do valor atribuído às estratégias cognitivas 
Galperin: implicaçôes educacionais da teoria de formação das ações mentais...

presentes na base orientadora, como se estivessem revestidas com o poder imanente do método. Essa noção só foi possível depois que se obteve sucesso no desgastante processo de elaboração e experimentação da base orientadora da ação, que comporta muitas idas e vindas. Mesmo depois de identificados determinados conceitos invariantes, permanece a investigação da melhor forma de apresentação da base orientadora da ação, como também o papel de controle do professor, adaptando-a às diferenças individuais dos aprendizes.

- O aprendiz é desencorajado a buscar uma solução independente para o problema ou a aprender novos conhecimentos sem a utilização da base orientadora da ação. Essa crítica faz uma análise dirigida apenas para as fases iniciais do processo de formação das ações mentais, onde a preocupação é realmente fornecer ao aprendiz todos os subsídios necessários à aprendizagem. Porém, uma vez que domine a base orientadora da ação, o aprendiz adquire autonomia de ação, estimulado pela fase de diversificação das situações-problema. Em longo prazo, a proposta pretende que o aprendiz seja capaz de formular, de maneira totalmente independente, a própria base orientadora da ação relacionada com outros tipos de habilidades e/ou conhecimentos a serem aprendidos.

- O modelo formativo-conceitual, preocupado em desenvolver um método eficaz de resolução de problemas, deixa de favorecer o desenvolvimento do pensamento criativo. Essa é a única crítica que Galperin (1989c, p. 80) reconhece como pertinente, não apenas como uma insuficiência do modelo formativo-conceitual, mas também em função da indefinição do conceito de criatividade e da falta de compreensão de suas características pela ciência.

Galperin (ibid., p. 80-81) esclarece que algumas críticas são decorrentes de uma dupla confusão em relação aos princípios que fundamentam o modelo formativo-conceitual.

Primeiro, a falta de uma distinção clara entre, de um lado, o processo de elaboração de um novo conceito pela produção científica, que parte da definiçãao teórica do conceito para a comprovação de sua exis- 
tência prática e, de outro lado, o processo de ensino-aprendizagem de um novo conceito pela ação educativa, que segue a ordem inversa do processo de produção científica, partindo da experiência prática, por meio da qual se conhece a estrutura do fenômeno, para chegar até à definição teórica final do conceito (ibid., p. 80).

Segundo, não se pode confundir a base orientadora da ação, que se restringe a um modelo operacional de caráter racional e externo que por meio da ação educativa pode se transformar em um mecanismo psicológico de ação do indivíduo -, com a complexidade que caracteriza o desenvolvimento das habilidades psicológicas do sujeito, não apenas como aprendiz ou um ser racional, mas como homem, que pensa, age e sente. Como já foi dito anteriormente, enquanto a base orientadora da ação se mantém constante, as orientaçôes próprias do sujeito variam de acordo com as características da sua personalidade e o refinamento das habilidades táticas obtido por meio da prática (Galperin, 1989c, p. 81).

A principal crítica, no entanto, também reconhecida por Galperin, que tentou reformular as etapas de formação das ações mentais, incluindo um sexto estágio, que na verdade não é o último, mas que perpassa e interfere em todos os anteriores, é a desconsideração dos aspectos relacionados com a motivação.

De uma maneira geral, acreditava-se que a seleção adequada de situações-problema passíveis de serem resolvidas mediante a instrumentação da ação, garantindo a obtenção de um resultado positivo, constituía-se, por si só, numa motivação intrínseca para a aprendizagem. Porém, ao longo das pesquisas, verificou-se que as questôes relacionadas à motivação possuem uma forte influência: a) das acepções pessoais de cada aprendiz, de acordo com suas expectativas e seu autoconceito; b) dos valores reforçados culturalmente; e c) da opinião das pessoas muito próximas afetivamente.

\section{O modelo de ensino formativo-conceitual em função do sujeito}

A tarefa educacional consiste na formação de métodos racionais que orientem o emprego das capacidades intelectuais na solução dos diferentes tipos de situações-problema. No entanto, por melhor que seja a proposta de ensino, não existe uma relação unívoca entre as condições de aprendizagem e as reações do aprendiz (Talízina, 1988, p. 47). 
Galperin: implicações educacionais da teoria de formação das ações mentais...

Permanecem as diferenças individuais na aprendizagem, a despeito do tratamento igualitário do professor. Além de discrepâncias no nível de habilidade de cada aprendiz, observa-se também a influência da experiência anterior e dos aspectos motivadores.

Apesar do modelo de ensino formativo-conceitual ter como diretriz central uma abordagem cognitivista, a participação ativa do aprendiz e os cuidados no acompanhamento da aprendizagem deixam claro que a proposta se realiza em função de um indivíduo concreto, que precisa ter sua liberdade de ação respeitada. A qualidade de ensino depende, portanto, da possibilidade efetiva de individualização do processo de ensino (idem, ibid.,p. 50).

Recebido em novembro de 2005 e aprovado em março de 2006.

\section{Referências bibliográficas}

GALPERIN, P.I. Desarrollo de las investigaciones sobre la formación de acciones mentales. Ciencia Psicológica en la URSS, Moscou, v. 1, 1959.

GALPERIN, P.I. On the notion of internalization. Soviet Psychology, Moscou, v. 5, n. 3, p. 28-33, 1967.

GALPERIN, P.I. Towards research on the intellectual development of the child. International Journal of Psychology, Amsterdã, v. 3, n. 4, p. $257-$ 271, 1968.

GALPERIN, P.I. Changing teaching methods is one prerequisite for increasing the effectiveness of the schooling process. Soviet Education, New York, v. 17, n. 3, p. 87-92, jan. 1975.

GALPERIN, P.I. The role of orientation in thought. Soviet Psychology, Moscou, v. 18, n. 2, p. 84-99, 1980.

GALPERIN, P.I. Study of the intellectual development of the child. Soviet Psychology, Moscou, v. 27, n 3, p. 26-44, may/june 1989a.

GALPERIN, P.I. Mental actions as a basis for the formation of thoughts and images. Soviet Psychology, Moscou, v. 27, n. 3, p. 4564, may/june $1989 \mathrm{~b}$. 
GALPERIN, P.I. Organization of mental activity and effectiveness of learning. Soviet Psychology, Moscou, v. 27, n. 3, p. 65-82, may/june 1989c.

GALPERIN, P.I. The problem of attention. Soviet Psychology, Moscou, v. 27, n. 3, p. 83-92, may/june 1989 d.

GALPERIN, P.I. Human instincts. Journal of Russian and East European Psychology, Armonk, v. 30, n. 4, p. 22-36, july/aug. 1992a.

GALPERIN, P.I. The problem of activity in soviet psychology. Journal of Russian and East European Psychology, Armonk, v. 30, n. 4, p. 37-59, july/aug. 1992b.

GALPERIN, P.I. Stage-by-stage formation as a method of psychological investigation. Journal of Russian and East European Psychology, Armonk, v. 30, n. 4, p. 60-80, july/aug. 1992c.

GALPERIN, P.I. Problems in psychology of activity. Journal of Russian and East European Psychology, Armonk, v. 33, n. 4, p. 18-31, july/aug. 1995.

GALPERIN, P.I.; LEONTIEV, A.N. Learning theory and programmed instruction. Soviet Education, New York, v. 7, n. 10, p. 7-15, 1965.

GULMANS, J.; VAN DEN VEER, R.; VOS, H. Concept formation: the view of a Podolsky. Journal of Russian and East European Psychology, Armonk, v. 33, n. 2, p. 81-103, mar./apr. 1995.

HAENEN, J. An interview with P. Ia. Galperin. Soviet Psychology, Moscou, v. 27, n. 3, p. 7-23, may/june 1989.

HAENEN, J. Introduction: Piotr Galperin and the content of soviet psychology. Journal of Russian and East European Psychology, Armonk, v. 30, n. 4, p. 3-21, july/aug. 1992.

HAENEN, J. Galperin instruction in the ZPD. Human Development, Basel, v. 43, n. 2, p. 93-98, mar./apr. 2000.

TALÍZINA, N.F. Conferencias sobre los fundamentos de la enseñanza en la educación superior. Universidad de la Habana: Departamento de Estudios para el Perfeccionamiento de la Educación Superior, 1984. 
Galperin: implicações educacionais da teoria de formação das ações mentais...

TALíZINA, N.F. Psicologia de la enseñanza. Moscou: Progreso, 1988. (Biblioteca de Psicologia Soviética).

VAN DER VEER, R. Some reflections concerning Galperin's theory. Human Development, Basel, v. 43, n. 2, p. 99-102, mar./apr. 2000.

WERTSCH, J.V. Galperin's elaboration of Vygotsky. Human Development, Basel, v. 43, n. 2, p. 103-106, mar./apr. 2000. 